* Aluna de Graduação em Direito na Escola Superior Dom Hélder Câmara. E-mail: marinasasouza@hotmail.com

** Pós-Doutor em Direito pela Universidade de Messina/ Itália. Doutor em Direito pela Pontifícia Universidade Católica de Minas Gerais. Mestre em Direito pela Pontifícia Universidade Católica de Minas Gerais. Especialista em Direito pela Universidade Gama Filho. Graduado em Direito e em Administração pela Universidade Federal de Minas Gerais. Editor da Revista Veredas do Direito (Qualis A1). Professor do Programa de Pós-graduação em Direito da Escola Superior Dom Helder Câmara. E-mail: elcionrezende@yahoo.com. br

\section{Responsabilidade Civil das \\ Mineradoras Decorrente da \\ REDUÇÃO DO TURISMO OCASIONADA \\ Pela Deterioração Ambiental}

Civil Liability of Mining Companies as

a Consequence of Tourism Redution That IS CAUSED BY ENVIRONMENTAL

DAMAGE

\section{Marina de Sá Rezende* Elcio Nacur Rezende**}

Como citar: REZENDE. Marina de Sá. REZENDE, Elcio Nacur. Responsabilidade civil das mineradoras decorrente da redução do turismo ocasionada pela deterioração ambiental. Revista do Direito Público, Londrina, v. 12, n. 1, p.119-143, abr. 2017. DOI: $10.5433 / 25794-11450-1.2017 v 12 n 1 p 119$. ISSN: $1980-511 X$.

Resumo: O presente artigo busca analisar a relação entre o ecoturismo e a mineração de forma a compreender se enseja a responsabilidade civil das mineradoras quando sua atividade acarreta a redução do movimento turístico na região explorada e, por consequência, redução econômica. Para tanto, analisar-se-á a legislação nacional respectiva, bem como a análise prática em alguns municípios de Minas Gerais, incluindo também a interpretação de algumas decisões judiciais do Tribunal de 
Justiça de Minas Gerais que impuseram o dever de reparar o dano causado pela atividade mineradora.

Palavras-chave: Mineração. Ecoturismo. Responsabilidade civil. Dano ambiental.

Abstract: This study analyzes the connection between ecotourism and mining operations; moreover, trying to understand if civil liability applies to mining companies when their activities reduces tourism in their affected areas, and, as a consequence, economic loss. Nonetheless, this research paper explores the applicable domestic legislation, including practical analysis' from cities of the Brazilian State of Minas Gerais, and examines court decisions from the Tribunal de Justiça de Minas Gerais - a state court - that obligated mining companies to undo some of their activities' damage.

Key words: Mining. Ecotourism. Civil liability. Environmental damage. 


\section{INTRODUÇÃO}

Reconhecido por suas riquezas naturais, o Brasil, como qualquer outro dos países ainda em desenvolvimento, vive em um conflito entre a exploração destes recursos e sua preservação ambiental. É importante notar que, dentre todas as atividades de exploração natural brasileira, as mais comuns são a exploração petrolífera, no mar, e a mineração. Em relatório do primeiro semestre de 2015 (de janeiro a junho) o Departamento Nacional de Produção Mineral (BRASIL, 2015) atesta que as exportações somente de ferro somaram a quantia de US\$ 7.163.189.030,00, sendo assim uma das exportações mais rentáveis nacionais. Entretanto, é importante notar que o Brasil exporta este material sem qualquer tipo de refinamento ou trabalho, podendo estes valores serem ainda maiores nos próximos anos com o desenvolvimento da mão de obra nacional. Em total, as exportações de exploração de minas resultaram em US\$ 11.906.747.899,00.

Da mesma forma, o turismo permanece de grande relevância para o reconhecimento internacional do Brasil. Não há como se falar do Brasil em questões internacionais sem mencionar as praias, a riqueza em área florestal e os diferentes biomas, que propiciam uma experiência turística completa - com regiões montanhosas e praias próximas, o país oferece atrações para todos. Recebendo eventos de relevância internacional, como a Copa do Mundo em 2014 e as Olimpíadas do Rio de Janeiro em 2016, o Brasil se mostrou um destino cada vez mais interessante para os turistas, tendo, somente em 2014, arrecadado US\$ 18.724.000,00, conforme dados do Banco Central do Brasil.

Entretanto, o turismo nacional depende, invariavelmente, das riquezas naturais brasileiras. Não obstante existirem regiões com atrações histórico-culturais diversas, as áreas naturais do Brasil ainda são grande 
atrativo para os turistas, como as praias da região nordeste do país, as áreas de pesca na região centro-oeste. E é nesse ponto que os interesses do turismo e da mineração se chocam, principalmente no interior do Brasil. Em Minas Gerais, especialmente, é possível visualizar o conflito entre a exploração minerária e o turismo, em especial o ecoturismo.

Assim, é necessário entender o que, de fato, rege o turismo sustentável, a alternativa que se apresenta sendo capaz de comungar preservação e exploração lucrativa. Para Swarbrooke (1999), devem ser os princípios do turismo sustentável:

1. Sustainable tourism is not just about protecting the environment; it is also concerned with long-term economic viability and social justice.

2. Initiatives designed to achieve sustainable tourism bring benefits to some people and costs to others. It is thus a highly political, rather than just a technocratic, field.

3. Sustainable tourism cannot be separated from the wider debate about sustainable development in general

4. There is a need for more critical evaluation of existing thinking and techniques in the area of sustainable tourism. Thre are to many "sacred cows" that are not being challenged rigorously enought or often enough. For example, where is the evidence that small-scale tourism is inherently more sustainable than mass tourism, regardless of the nature of the environment in which it takes place?

5. Progress towards more sustainable forms of tourism will depend far more on the activities of the industry and the attitudes of tourists, than on the actions of public sector bodies (SWARBROOK, 1999, p. VII).

O presente artigo busca analisar como será a responsabilidade civil das mineradoras nos casos em que sua atividade prejudica o turismo 
na região exploradora e, por consequência, a redução econômica.

\section{ASPECTOS FÁTICOS E JURÍdICOS DA ATIVIDADE MINERADORA NO BRASIL}

A Constituição da República de 1988 dispõe, constituindo direito fundamental de terceira geração, em seu art. 265:

Todos têm direito ao meio ambiente ecologicamente equilibrado, bem de uso comum do povo e essencial à sadia qualidade de vida, impondo-se ao Poder Público e à coletividade o dever de defendê-lo e preservá-lo para as presentes e futuras gerações (BRASIL, 1988).

Porém, o dever de preservar o meio ambiente, que se constitui cláusula pétrea, deve ser balanceado com o objetivo fundamental da República do Brasil em seu art. $3^{\circ}$, II garantir o desenvolvimento nacional. Assim, nas noções de Alexy (2003), os princípios não se excluem, mas se limitam no sistema de freios e contrapesos não de forma que deixem de se aplicar em uma determinada situação, mas que alcancem um equilíbrio razoável para a incidência de ambos.

Sendo assim, impõe-se ao poder público a fiscalização e o cuidado na concessão de exploração de recursos naturais, questão também orientada na Constituição, no mesmo artigo, em seu parágrafo $1^{\mathrm{o}}$ :

Para assegurar a efetividade desse direito, incumbe ao Poder Público:

$[\ldots]$

IV- exigir, na forma da lei, para instalação de obra ou atividade potencialmente causadora de significativa degradação do meio ambiente, estudo prévio de 
impacto ambiental, a que se dará publicidade. (BRASIL, 1988)

Acrescenta-se a esta disposição, outro ponto marcante na disposição constitucional, que obriga, em seu art. $265, \S 3^{\circ}$ " $§ 3^{\circ} \mathrm{As}$ condutas e atividades consideradas lesivas ao meio ambiente sujeitarão os infratores, pessoas físicas ou jurídicas, a sanções penais e administrativas, independentemente da obrigação de reparar os danos causados." (BRASIL, 1988). Dessa forma, a Constituição impõe ao infrator a responsabilidade civil objetiva, aquela que independe de culpa para que se permita a responsabilização do agente, sendo, entretanto, passível de exclusão de responsabilidade em caso de excludente de ilicitude, configurando-se assim, a teoria do risco criado, que conceituada por Steigleder (2011):

No Direito brasileiro, não se indaga sobre a licitude da atividade. A existência de licenciamento ambiental, observância das condicionantes, dos limites de emissão de poluentes, autorizações administrativas, dentre outras, não têm o condão de excluir a responsabilidade pela reparação (apud BEDRAN; MAYER, 2010, p. 55).

Para compreensão dos danos ambientais causados pela mineração é obstante perceber noções básicas da área. Não obstante genericamente denominada a mineração, a extração do minério como atividade específica denomina-se lavra, conforme o art. 36 do Decretolei $n^{o}$. 227 de 1967: "Entende-se por lavra o conjunto de operações coordenadas objetivando o aproveitamento industrial da jazida, desde a extração das substâncias minerais úteis que contiver, até o beneficiamento 
das mesmas" (BRASIL, 1967). E é a lavra e seus resíduos que promovem a degradação ambiental.

No Decreto-lei $n^{\circ} .227$, dentre as obrigações daquele que explora a lavra, no art. 47, encontra-se a seguinte disposição:

Art. 47. Ficará obrigado o titular da concessão, além das condições gerais que constam deste Código, ainda, às seguintes, sob pena de sanções previstas no Capítulo V:

$[\ldots]$

VIII - Responder pelos danos e prejuízos a terceiros, que resultarem, direta ou indiretamente, da lavra". (BRASIL, 1967).

Está aí a disposição expressa que permite a responsabilização civil daquele que, pela lavra, prejudicar a terceiros, sem discriminar quem são os terceiros contemplados pela indenização.

Ademais, é necessário entender o que se define - legalmente por impacto ambiental. Conforme a Resolução 1/1986 do CONAMA, em seu artigo $1^{\circ}$ :

Para efeito desta Resolução, considera-se impacto ambiental qualquer alteração das propriedades físicas, químicas e biológicas do meio ambiente, causada por qualquer forma de matéria ou energia resultante das atividades humanas que, direta ou indiretamente, afetam:

I - a saúde, a segurança e o bem-estar da população;

II - as atividades sociais e econômicas;

III - a biota;

IV - as condições estéticas e sanitárias do meio ambiente;

$\mathrm{V}$ - a qualidade dos recursos ambientais (CONSELHO NACIONAL DO MEIO AMBIENTE, 1986). 
Ademais, para Paulo Affonso Leme Machado (2013), a exploração mineral é regida por alguns princípios, a saber: o princípio da precaução, disposto na Declaração do Rio de 1992 como princípio 15:

Com o fim de proteger o meio ambiente, o princípio da precaução deverá ser amplamente observado pelos Estados, de acordo com suas capacidades. Quando houver ameaça de danos graves ou irreversíveis, a ausência de certeza científica absoluta não será utilizada como razão para o adiamento de medidas economicamente viáveis para prevenir a degradação ambiental (RAMID; RIBEIRO, 1992, p. 157).

O princípio do desenvolvimento sustentado, que, conforme José Afonso da Silva (2010), orienta que “[...] se há recursos não renováveis, os minerais são os típicos, de sorte que devem ser utilizados de forma a evitar o perigo de seu esgotamento futuro [...]."

Por fim, nos termos da Lei $n^{\circ}$. 7.805/89, compreende-se, em específico à mineração - diferente do disposto na Constituição da República, o dever de reparar o meio ambiente degradado por parte do agente explorador da mineração, em seu art. 19: "O titular de autorização de pesquisa, de permissão de lavra garimpeira, de concessão de lavra, de licenciamento ou de manifesto de mina responde pelos danos causados ao meio ambiente" (BRASIL, 1989). Sendo assim, é necessário observar que, quando se refere ao sujeito ativo na norma, o legislador não determina ser somente pessoa natural ou jurídica, sendo assim, aplicável o dispositivo a ambos.

\section{ASPECTOS FÁticos E JURÍdICOS DA ATIVIDADE}




\section{TURÍSTICA NO BRASIL}

Atividade muito explorada no Brasil, a Organização Mundial do Turismo conceitua este fenômeno de diversas formas, em conceitos que evoluem com o passar dos anos, dentre estes, destacam-se dois conceitos um de 1991, na Conferência de Ottawa:

[...] as atividades realizadas pelas pessoas durante suas viagens a e estadias em lugares diferentes de seu entorno habitual, por um período de tempo consecutivo inferior a um ano, tendo em vista lazer, negócios ou outros motivos não relacionados ao exercício de uma atividade remunerada no lugar visitado (OMT, 2001, p. 38).

E outro conceito de 2008, também da OMT “[...] o turismo é um fenômeno social, cultural e econômico, que envolve o movimento de pessoas para lugares fora do seu local de residência habitual, geralmente por prazer" (OMT, 2010).

Conceituado o turismo é necessário entender o ecoturismo, conceituado pelo Ministério do Turismo (BRASIL, 2010):

Ecoturismo é um segmento da atividade turística que utiliza, de forma sustentável, o patrimônio natural e cultural, incentiva sua conservação e busca a formação de uma consciência ambientalista por meio da interpretação do ambiente, promovendo o bem-estar das populações.

Sendo assim, o meio ambiente e o patrimônio cultural são pontos basilares para o exercício do ecoturismo. Conceitua o Direito brasileiro, no art. $3^{\circ}$, I da Lei ${ }^{\circ} .6938 / 81$ o que se entende por meio ambiente, 
sendo este "[...] o conjunto de condições, leis, influências e interações de ordem física, química e biológica, que permite, abriga e rege a vida em todas as suas formas" (BRASIL, 1981). Assim, as noções de proteção e preservação ambiental são ainda mais amplas que a mera preservação do ambiente natural. Perpassa também por aspectos químicos e biológicos, não sendo possível ignorar que ao ecoturismo também é necessário respeitar os ambientes em que se encontra.

Inclui-se dentro do ecoturismo o patrimônio natural, conceituado na Convenção Para a Proteção do Patrimônio Mundial, Cultural e Natural da UNESCO, elaborada em 1972 e promulgada pelo Brasil, em seu Artigo 2 como:

[...] - os monumentos naturais constituídos por formações físicas e biológicas ou por conjuntos de formações de valor universal excepcional do ponto de vista estético ou científico;

- as formações geológicas e fisiográficas, e as zonas estritamente delimitadas que constituam habitat de espécies animais e vegetais ameaçadas de valor universal excepcional do ponto de vista estético ou científico, - os sítios naturais ou as áreas naturais estritamente delimitadas detentoras de valor universal excepcional do ponto de vista da ciência, da conservação ou da beleza natural (BRASIL, 1977).

Também é intrínseca ao ecoturismo a preservação do patrimônio cultural, definido pela UNESCO em 1972 na Convenção para a Proteção do Patrimônio Mundial, Cultural e Natural no Artigo 1, como:

[...] - os monumentos: obras arquitetônicas, esculturas ou pinturas monumentais, objetos ou estruturas arqueológicas, inscrições, grutas e conjuntos de valor universal excepcional do ponto de vista da 
história, da arte ou da ciência, - os conjuntos: grupos de construções isoladas ou reunidas, que, por sua arquitetura, unidade ou integração à paisagem, têm valor universal excepcional do ponto de vista da história, da arte ou da ciência, - os sítios: obras do homem ou obras conjugadas do homem e da natureza, bem como áreas, que incluem os sítios arqueológicos, de valor universal excepcional do ponto de vista histórico, estético, etnológico ou antropológico (UNESCO, 1972).

A definição de patrimônio cultural também pode ser encontrada no texto constitucional brasileiro que expõe, em seu artigo 216 que:

Constituem patrimônio cultural brasileiro os bens de natureza material e imaterial, tomados individualmente ou em conjunto, portadores de referência à identidade, à ação, à memória dos diferentes grupos formadores da sociedade brasileira, nos quais se incluem:

I - as formas de expressão;

II - os modos de criar, fazer e viver;

III - as criações científicas, artísticas e tecnológicas; IV - as obras, objetos, documentos, edificações e demais espaços destinados às manifestações artísticoculturais;

V - os conjuntos urbanos e sítios de valor histórico, paisagístico, artístico, arqueológico, paleontológico, ecológico e científico (BRASIL, 1988).

Dessa forma, diversamente do que se pensa, não trata o ecoturismo somente de ambientes intocados pela influência humana. Trata também de patrimônio histórico-cultural, que deve ser igualmente respeitado por sua relevância ambiental (visto que meio ambiente não é só o que se entende por "natureza" ou os recursos naturais). 
No já mencionado material referente ao Ecoturismo (BRASIL, 2010) do Ministério do Turismo, o governo brasileiro propõe pontos importantes para o desenvolvimento do Ecoturismo, dentre eles a gestão, proteção e conservação dos recursos naturais, para “[...] adoção de estratégias e ações para minimizar possíveis impactos negativos da visitação turística por meio do uso de um modelo de gestão sustentável da atividade" (BRASIL, 2010); e a preservação da paisagem, que "[...] é um importante elemento na caracterização do segmento, pois são os locais preservados ou conservados e sua atmosfera que compõem o cerne da motivação dos turistas" (BRASIL, 2010).

Assim, no processo de licenciatura ambiental para a autorização estatal para a exploração de atividade que cause danos ao meio ambiente, é necessário considerar " [...] os impactos do empreendimento e as medidas destinadas a mitigação, compensação e controle desses impactos [...]" (BRASIL, 2010, p. 48).

Quanto à relevância econômica do turismo para o Brasil, dados de 2014 divulgados no portal do Ministério do Turismo em parceria com a Universidade de Economia de Oxford demonstram que " [...] contribui com $9,2 \%$ do PIB no país, o que equivale a $\mathrm{R} \$ 443,7$ bilhões e coloca o país na sexta posição mundial" (BRASIL, 2014). Esse valor equivale a US\$ 205,6 bilhões. Já os dados do IBGE referentes ao mesmo período são um pouco distintos. O Instituto Brasileiro de Geografia e Estatística afirma que o turismo representou $3,5 \%$ do PIB, totalizando valor de US\$ 77,6 bilhões, já que:

[...] leva em conta os impactos mais amplos que incluem toda a cadeia produtiva do setor, como geração de empregos diretos e indiretos, investimentos com a construção de novos empreendimentos, gastos 
públicos com segurança, saneamento, transporte, [...], entre outros (BRASIL, 2014).

No ranking internacional, também de 2014, o Brasil é a $6^{\text {a }}$ economia do turismo no mundo.

Swarbrooke (1999) elenca algumas vantagens que o ecoturismo produz. São elas:

[...] - provides economic benefits for local people and can provide revenue for conservation projects tends to be quite small scale an carefully managed - involves tourists who are well aware of the potential dangers of tourism an at least should behave more sensitively than many other tourists - raises awareness of issues amongst the tourists because of their first hand experience to the issues in the field. These tourists may then become involved in active campaigning on these issues when they come home. It is also a form of tourism which is very popular with tourists. (SWARBROOKE, 1999, p. 319).

\section{A RELAÇÃO ENTRE O ECOTURISMO E A MINERAÇÃO}

Muito comum na região de Minas Gerais é a coincidência entre a área de ecoturismo com a área de mineração. Isto porque, o minério fica nas montanhas, que atraem os turistas para o turismo de aventura, como escalada, rapel e trilha, além da vegetação natural e o contato com a natureza. Na impossibilidade de realizar a lavra sem desmatar a montanha, escavar e produzir detritos - muitas vezes tóxicos - a mineração e o ecoturismo muitas vezes exigem atividades opostas para se manterem em uma determinada região. Assim, conforme Lopes et al. (2010) colocado por "[...] a conservação ambiental e, com ela, o ecoturismo se tornam 
pressionados na medida em que se configuram diferentes formas de uso do solo, seja para empreendimentos imobiliários e industriais ou, especificamente, para a extração mineral". Neste relevante estudo, as autoras demonstram a visão que possui a comunidade de 4 regiões da RPPN do Santuário Caraça, observando, através de entrevistas, que:

As histórias, as ruínas, a natureza, a paisagem e o seu povo são elementos que compõem um cenário positivo para se contrapor às pressões do desenvolvimento econômico, da extração mineral, da especulação imobiliária, das restrições ambientais. No entanto, os fatores alicientes nas ofertas de empregos na indústria contemporânea tendem a se tornar preponderantes nas decisões da população em detrimento da opção pela vida no campo. (LOPES et al., 2010, p. 403).

Fleischer (2007), desenvolveu interessante estudo sobre a relação entre a mineração e o ecoturismo, nos municípios mineiros de Lagoa Santa e São Tomé das Letras, e afirma:

O desenvolvimento do ecoturismo está em direto conflito com a mineração. A lógica do ecoturismo está principalmente vinculada à conservação: é uma atividade que exige um planejamento calculado, que leve em consideração possíveis impactos aos recursos naturais e alternativas para uma execução sustentável (FLEISCHER, 2007,)

Devido ao interesse, em específico na cidade de São Tomé das Letras, pelo desenvolvimento do ecoturismo como solução para o fim da atividade mineradora, Fleischer (2007) observa que a "[...] prefeitura discute as implicações de impor sanções à atividade de mineração para 
que essa se conforme com as necessidades do ecoturismo e da preservação histórica". Entretanto, demonstra também que é impossível ignorar a relevância da mineração para o desenvolvimento econômico e social neste município, visto que a atividade emprega $50 \%$ da mão de obra da cidade (conforme os dados de 2007). Surgiu assim, em São Tomé das Letras uma divergência entre a população:

A manutenção do status quo em relação à mineração tem relação com a necessidade de manter empregos na cidade. Essa disputa entre mineração e meio ambiente também se tornou uma disputa de classes, entre moradores recentes que são donos de empreendimentos de turismo e moradores mais antigos que trabalham nas pedreiras. (FLEISCHER, 2007)

Ademais, a incompatibilidade entre o ecoturismo e a mineração está muito além do que se pensa inicialmente no município de São Tomé das Letras. Fleischer (2007) observou que a “[...] mineração é a atividade econômica mais incompatível com o turismo e, no caso de São Tomé das Letras, está destruindo atrativos naturais (paisagem e patrimônio) e gerando pressão sobre recursos naturais usados pelo ecoturismo local (água e vegetação)". Além disso, o trânsito de caminhões e o uso de dinamite para obtenção do minério alteram a estrutura dos prédios históricos, que com a trepidação tem sua edificação abalada.

$\mathrm{O}$ risco que o trânsito traz para os edifícios históricos foi analisado na cidade mineira de Ouro Preto. Em dissertação publicada em 2011, Luiz Mauro de Resende (2011), engenheiro civil, explica um dos fatores que acentuam a degradação dos prédios:

Os danos ao patrimônio com origem nas vibrações 
mecânicas são mais intensos em cidades históricas devido às características das suas edificações e pelo tipo de pavimentação das suas vias. Estas edificações são mais sensíveis às vibrações provocadas pelo trânsito de veículos principalmente pela rusticidade do pavimento das suas ruas, que geralmente são em blocos prismáticos de pedra ou paralelepípedos (poliedro regular de rocha ígnea), o que proporciona uma superfície extremamente irregular. Esta irregularidade propicia a geração de mais níveis elevados de vibração frente ao trânsito de veículos automotores (RESENDE, 2011).

Assim, pode-se visualizar que, com o trânsito de caminhões carregados de minério pelas ruas e estradas das cidades onde há lavra, os edifícios estarão sujeitos às vibrações descritas. Se é possível observar esse fenômeno com carros de passeio leves, só tende a se intensificar com caminhões carregados por toneladas, além de existir, em grande parte das cidades no estado de Minas Gerais que possuem lavra, o pavimento descrito, conhecido como paralelepípedo, além de terem ruas estreitas e construções muito próximas à calçada. Essas vibrações causam os efeitos descritos:

Efeitos sobre as Edificações: Os danos causados pelas vibrações podem afetar as edificações, tanto em seus elementos estruturais como em seus elementos estéticos. Os danos estruturais em geral se dão sobre edificações antigas, alargando rachaduras, por exemplo. Os danos estéticos se dão com o rompimento de acabamentos, deslocamento das telhas, trincas, etc., que, normalmente, não afetam a segurança das edificações. A tabela abaixo apresenta uma comparação entre as reações humanas e os efeitos nas edificações em função das vibrações, 
definidas pela velocidade de pico das partículas (RESENDE, 2011).

Dessa forma, é possível observar as seguintes conexões: o ecoturismo possui intrínseca ligação com o meio ambiente. Este meio ambiente não se restringe apenas ao patrimônio natural, sendo também abarcado pelo patrimônio cultural. As edificações históricas que fazem parte do patrimônio cultural possuem estrutura antiga, normalmente em cidades sem calçamento de asfalto estando também próximas à calçada. Soma-se aos fatores já descritos que os caminhões das mineradoras passam carregados e com peso que promove ainda mais trepidação e vibração nos edifícios. Este é um inesperado impacto da mineração no ecoturismo.

É interessante observar como se dá o dano ao edifício pela trepidação. Conforme Resende (2011): “As vibrações colocam as construções em perigo devido ao movimento induzido nas suas bases". A fundação do edifício tende a seguir o movimento do terreno, mas devido a efeitos de inércia, a sua massa opõe-se a ser deslocada e a seguir o movimento da base.

Além do referido impacto, Kanno (2008), aponta outra consequência do tráfego de carros em regiões de preservação de patrimônio cultural: a poluição do ar. Assim descreve:

Dentre os fatores que decorrem da ação dos poluentes, há o acúmulo das partículas que são levadas pelo vento e depositadas, em parte, no interior da estrutura das alvenarias e rebocos devido à porosidade dos materiais, provocando manchas de difícil remoção. E quando há uma grande concentração desses depósitos forma-se uma camada de poluentes e fuligem [...] 


\section{(ALMEIDA, 2005 apud KANNO, 2008)}

Ocorre também a corrosão de partes metálicas, como aço, é causado pelos gases ácidos, em especial o enxofre, além de desgaste na pintura, com escurecimento, perda da cor e acúmulo de sujeira. As cidades em que se instala a atividade mineradora não possuem, em regra, grande trânsito de veículos que não sejam os da própria mineração. Assim, não só o peso destes, mas também as partículas que eles espalham, não só pelo escapamento mas também pelo pó do minério, geram prejuízos estéticos e estruturais às edificações históricas.

\section{A RESPONSABILIDADE CIVIL DA MINERAÇÃO FRENTE AOS SUJEITOS QUE EXPLORAM O ECOTURISMO}

O Código Civil de 2002 determina, em seus artigos 186 e 187, quais condutas serão consideradas ilícitas e, assim, passíveis de reparação pelo agente, conforme segue: “Art. 186. Aquele que, por ação ou omissão voluntária, negligência ou imprudência, violar direito e causar dano a outrem, ainda que exclusivamente moral, comete ato ilícito." e "Art. 187. Também comete ato ilícito o titular de um direito que, ao exercê-lo, excede manifestamente os limites impostos pelo seu fim econômico ou social, pela boa-fé ou pelos bons costumes" (BRASIL, 2002).

Sendo assim, a atividade mineradora que, de qualquer forma, trouxer prejuízo ao setor do turismo gerará a obrigação de reparar o dano causado, ainda que o faça exercendo direito de forma excessiva, como nos casos em que há abuso da área explorada ainda que com concessão estatal.

Ademais, conforme as disposições já citadas - que se referem 
a dano ambiental e à atividade mineradora - pode-se concluir que, além das disposições do Código Civil, se aplicarão também as disposições constitucionais e da legislação específica.

Pode-se também compreender, conforme as disposições referentes à perdas e danos nas obrigações, que o dever de não prejudicar o ecoturismo com a exploração das reservas minerais constitui obrigação de não fazer e, sendo assim, nos termos do "Art. 251. Praticado pelo devedor o ato, a cuja abstenção se obrigara, o credor pode exigir dele que o desfaça, sob pena de se desfazer à sua custa, ressarcindo o culpado perdas e danos" (BRASIL, 2002).

Constituem-se as perdas e danos pelo dano emergente - causado pela ação - e o lucro cessante - os prejuízos futuros, os valores que não serão percebidos por consequência do dano causado.

Assim, na hipótese da exploração mineral causar prejuízo ao ecoturismo, será necessária a interposição de reclamação judicial para que, produzindo as provas cabíveis, permaneça demonstrado o dano ambiental causado pela mineração que, embora expressa obrigação legal, não foi reparado e causou, assim, prejuízo para a exploração turística do local.

Conforme o art. 927, Código Civil de 2002 “Art. 927. Aquele que, por ato ilícito (arts. 186 e 187), causar dano a outrem, fica obrigado a repará-lo". Assim, conforme o parágrafo único: "Haverá obrigação de reparar o dano, independentemente de culpa, nos casos especificados em lei, ou quando a atividade normalmente desenvolvida pelo autor do dano implicar, por sua natureza, risco para os direitos de outrem." (BRASIL, 2002).

Entretanto, como seria possível, na legislação brasileira, comprovar ato ilícito por parte da mineradora? Começa a resposta para 
tal questionamento no conceito de poluição dado pela Lei 6.938 que, em seu art. $3^{\text {o }}$, III, assim conceitua a poluição: “' [...] a degradação da qualidade ambiental resultante de atividades que direta ou indiretamente: b) criem condições adversas às atividades sociais e econômicas" (BRASIL, 1981). Sendo assim, há vedação expressa que obsta à mineração de prejudicar o ecoturismo, aqui entendido como atividade econômica mediante à qual hotéis, agências de turismo, restaurantes, guias, camping 's, além de inúmeras outras formas de empreendimento, se sustentam.

Necessário também será entender se a mineradora poderá ser considerada, para efeitos legais, como poluidora. Novamente a Lei $\mathrm{n}^{\mathbf{0}}$. 6.938 traz a resposta, ainda em seu art. $3^{\circ}$, IV:'[...] IV - poluidor, a pessoa física ou jurídica, de direito público ou privado, responsável, direta ou indiretamente, por atividade causadora de degradação ambiental." (BRASIL, 1981).

Incorre assim a mineradora na obrigação de pagar, conforme o princípio do poluidor pagador. Tal princípio está previsto no art. $4^{\mathrm{o}}$, VII: "[...] à imposição, ao poluidor e ao predador, da obrigação de recuperar e/ou indenizar os danos causados e, ao usuário, da contribuição pela utilização de recursos ambientais com fins econômicos.” (BRASIL, 1981).

Comprovando-se assim que houve prejuízo econômico ao ecoturismo causado pela poluição, somado à identificação da mineradora como poluidora (seja por ação ou omissão), independente de dolo ou culpa (conforme a responsabilidade civil objetiva), surge ao poluidor a obrigação de reparar os danos aos quais deu causa.

\section{CONCLUSÃO}


Tanto a exploração mineral quanto o ecoturismo têm grande valor na economia nacional e na movimentação de renda nas cidades em que as atividades ocorrem. Dessa forma, por tratarem-se de atividades diametralmente opostas, os conflitos são constantes e dificilmente conciliáveis com a coexistência de ambos setores.

Inicialmente, acredita-se que o único impacto causado pela mineração é diretamente pela lavra que, via de regra, desgasta o solo, prejudica a vegetação e promove poluição dos rios próximos, fatores esses plenamente veiculados na mídia. Não obstante, existem impactos não tão divulgados, como o prejuízo direto aos edifícios históricos, decorrentes da trepidação (vibração) do trânsito acentuado, bem como da poeira do minério e dos caminhões, incluindo nestes também a fumaça dos escapamentos, que prejudica a estética dos edifícios.

Entretanto, é importante recordar que, na maioria dos casos, a mineração já havia se instalado antes do ecoturismo, estando já consolidada na cidade a necessidade da extração mineral, por ser basilar para a economia dos pequenos municípios. Soma-se a isso a já consolidada jurisprudência que obriga à mineradora a reparar os danos ambientais aos quais deu causa.

Dessa forma, deverá o juiz analisar no caso concreto é a necessidade de se imputar indenização pelo dano ambiental não recuperado, bem como pela violação da obrigação de não causar dano ao meio ambiente.

Não é possível descartar também a convivência das duas atividades: as mineradoras incentivando o ecoturismo, evitando ao máximo prejudicar as áreas que interessam aos turistas e evitando o trânsito dos caminhões por dentro das cidades, além de promover o desenvolvimento econômico local. 


\section{REFERÊNCIAS}

ALEXY, Robert. On balancing and subsumption. A structural comparision. Ratio Juris, Malden, v. 16, n. 4, p. 433-449, 2003.

BEDRAN, Karina Marcos; MAYER, Elizabeth A responsabilidade civil por danos ambientais no direito brasileiro e comparado: teoria do risco criado versus teoria do risco integral. Veredas do Direito, Belo Horizonte, v. 10, n. 19, p.45-88, jan./jun. 2013.

\section{BRASIL. Constituição (1988). Constituição da República}

Federativa do Brasil. Disponível em: $<$ http://www.planalto.gov.br/ ccivil_03/constituicao/constituicao.htm>. Acesso em: 6 jun. 2016.

BRASIL. Decreto $\mathbf{n}^{\mathbf{0}} \mathbf{8 0 . 9 7 8}$, de 12 de dezembro de 1977. Promulga a Convenção Relativa à Proteção do Patrimônio Mundial, Cultural e Natural, de 1972. Disponível em: <http://legis.senado.gov.br/ legislacao/ListaPublicacoes.action?id=124463>. Acesso em: 20 fev. 2017.

BRASIL. Decreto-Lei no 227, de 28 de fevereiro de 1967. Dá nova redação ao Decreto-lei no 1.985 , de 29 de janeiro de 1940. (Código de Minas). Disponível em: <http://www.planalto.gov.br/ccivil_03/ decreto-lei/Del0227.htm>. Acesso em: 6 jun. 2016.

BRASIL. Departamento Nacional de Produção Mineral. Informe mineral. Brasília, 2015a. Disponível em: <http://www.dnpm.gov.br/ dnpm/informes/informe-mineral-2015-1o-semestre $>$. Acesso em: 14 abr. 2016.

BRASIL. Lei $\mathbf{n}^{\mathbf{0}} \mathbf{1 0 . 4 0 6}$, de 10 de janeiro de 2002. Institui o Código Civil. Disponível em: <http://www.planalto.gov.br/ccivil_03/ leis/2002/L10406.htm>. Acesso em: 2 jun. 2016. 
BRASIL. Lei no 6.938, de 31 de agosto de 1981. Dispõe sobre a Política Nacional do Meio Ambiente, seus fins e mecanismos de formulação e aplicação, e dá outras providências. Disponível em: $<$ http://www.planalto.gov.br/ccivil_03/leis/L6938.htm>. Acesso em: 2 jun. 2016.

BRASIL. Lei $\mathbf{n}^{\mathbf{0}} \mathbf{7 . 8 0 5}$, de 18 de julho de 1989. Altera o DecretoLei no 227 , de 28 de fevereiro de 1967, cria o regime de permissão de lavra garimpeira, extingue o regime de matrícula, e dá outras providências. Disponível em: < http://www.planalto.gov.br/ccivil_03/ leis/L7805.htm>. Acesso em: 20 fev. 2017.

BRASIL. Ministério do Turismo. Economia do turismo cresce no Brasil. 2014. Disponível em: < http://www.turismo.gov.br/ultimasnoticias/2199-economia-do-turismo-cresce-no-brasil.html > . Acesso em: 10 jan. 2016.

BRASIL. Ministério do Turismo. Ecoturismo: orientações básicas. 2. ed. Brasília, 2010.

CONAMA - CONSELHO NACIONAL DO MEIO AMBIENTE. Resolução CONAMA no 001, de 23 de janeiro de 1986. Disponível em: <http:/www.mma.gov.br/port/conama/ res/res86/res0186.html>. Acesso em: 20 fev. 2017.

FLEISCHER, David Ivan Rezende. Ecoturismo ou “Éca! Turismo!": Sustentabilidade e adaptabilidade em uma cidade mineira. Revista Anthropológicas, Pernambuco, ano 11, v. 18, n. 1, p. 171-204, 2007.

KANNO, Simone Izumi Kubo. Metodologia de avaliação dos impactos dos transportes urbanos em áreas de preservação histórica. 2008. Dissertação (Mestrado em Engenharia Civil) Universidade Federal de Uberlândia, Uberlândia.

LOPES, Danielle Alves et al. Ecoturismo, cultura e comunidades: reflexões sobre o entorno da RPPN Santuário do Caraça (MG). 
Revista Brasileira de Ecoturismo, São Paulo, v. 3, n. 3, p. 382-407, 2010.

MACHADO, Paulo Affonso Leme. Direito ambiental brasileiro. 21. ed. São Paulo: Editora Malheiros, 2013.

OMT - ORGANIZAÇÃO MUNDIAL DO TURISMO. Cuenta satélite de turismo: Recomendaciones sobre el marco conceptual, 2008. Luxemburgo, 2010. (Estudios de métodos - Serie F No. 80/ Rev.1).

OMT - ORGANIZAÇÃO MUNDIAL DO TURISMO. Introdução ao turismo. São Paulo: Roca, 2001.

RAMID, João; RIBEIRO, Antônio. Declaração do Rio de Janeiro. Estudos Avançados, v. 6, n. 15, p. 153-159, 1992.

RESENDE, L. M. Análise do risco de danos por vibração mecânica nos monumentos setecentistas do caminho tronco de Ouro

Preto. 2011. Dissertação (Mestrado em Engenharia de Materiais) Universidade Federal de Ouro Preto, Ouro Preto, 2011.

SILVA, José Afonso da. Direito ambiental constitucional. 8. ed. São Paulo: Malheiros, 2010.

SWARBROOKE, John. Sustainable tourism management. New York: CABI Publishing, 1999.

UNESCO - ORGANIZAÇÃO DAS NAÇÕES UNIDAS PARA A EDUCAÇÃO, A CIÊNCIA E A CULTURA. Convenção para a proteção do patrimônio mundial, cultural e natural. 1972. Disponível em: http://www.mma.gov.br/estruturas/sbs_dap/_arquivos/ convpatrimoniomundial.pdf. Acesso em: 20 fev. 2017.

Como citar: REZENDE. Marina de Sá. REZENDE, Elcio Nacur. Responsabilidade civil das mineradoras decorrente da redução 
do turismo ocasionada pela deterioração ambiental. Revista do Direito Público, Londrina, v. 12, n. 1, p.119-143, abr. 2017. DOI: 10.5433/25794-11450-1.2017v12n1p119. ISSN: 1980-511X.

Recebido em: 27/04/2016

Aprovado em: 21/02/2017 